\title{
COMPARISON OF ULTRASOUND GUIDED BILATERAL SUBCOSTAL TRANSVERSUS ABDOMINIS PLANE BLOCK VERSUS LOCAL INFILTRATION OF PORT SITE WITH BUPIVACAINE IN PATIENTS UNDERGOING LAPAROSCOPIC CHOLECYSTECTOMY UNDER GENERAL ANESTHESIA
}

\author{
Bandana Paudel ${ }^{1^{*}}$, Sumitra Paudel ${ }^{2}$,Pramod Rai ${ }^{3}$, Sagar Dahal ${ }^{4}$, Anuja Pokhrel ${ }^{4}$
}

\begin{abstract}
Affiliation
1. Assistant Professor/Départment of Anaesthesiology, Nobel Medical College Teaching Hospital, Nepal

2. Medical Officer, Départment of Anaesthesiology, Nobel MedicalCollegeTeaching Hospital, Nepal

3. Consultant, Départment of Anaesthesiology, Nobel Medical College Teaching Hospital, Nepal

4. Lecturer, Départment of Anaesthesiology, Nobel Medical College Teaching Hospital, Nepal
\end{abstract}

\section{ARTICLE INFO}

Received : 18 October, 2021

Accepted : 05 January, 2022

Published : 21 February, 2022

(C) Authors retain copyright and grant the journal right of first publication with the work simultaneously licensed under Creative Commons Attribution License CC - BY 4.0 that allows others to share the work with an acknowledgment of the work's authorship and initial publication in this journal.

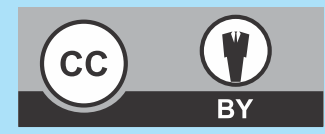

\section{ORA 284}

DOI: https://doi.org/10.3126/bjhs.v6i3.43214

* Corresponding Author

Dr. Bandana Paudel

Assistant Professor

Département of Anaesthesiology

Nobel Medical College Teaching Hospital, Nepal

Email: dr.bandana.nobel@gmail.com

ORCID: https://orcid.org/0000-0001-8225-0983

\section{Citation}

Comparison of Ultrasound Guided Bilateral Subcostal Transversus abdominis Plane Block Versus Local Infiltration of Port Site with Bupivacaine in Patients Undergoing Laparoscopic Cholecystectomy Under General Anesthesia. Bandana Paudel, Sumitra Paudel, Pramod Rai, Sagar Dahal, Anuja Pokhrel. BJHS 2021;6(3)16. 1642-1646.

\section{ABSTRACT}

\section{Introduction}

Patients undergoing laparoscopic cholecystectomy have moderate post-operative pain in the early post-operative period. There are several modalities to manage pain in the postoperative period. Subcostal transversus abdominis plane block is one of the effective methods for pain management. The objective of our study was to compare the analgesic efficacy of subcostal transversus abdominis block versus local infiltration at the port site with bupivacaine in patients undergoing Laparoscopic cholecystectomy under general anesthesia.

\section{Methodology}

This is a prospective randomized study of 60 patients of age group 18 - 60 years of either gender, of ASA PS I and II scheduled for laparoscopic cholecystectomy under general anesthesia and were randomly divided into two groups.At the end of the surgery $20 \mathrm{ml}$ of $0.25 \%$ bupivacaine was administered with ultrasound guided subcostal transversus abdominis plane block bilaterally in group $T$ and local infiltration at the port sites in group L. Visual analogue scale at 0, 2, 6, 12 and 24 hours at rest, time of rescue analgesia and opioids consumption were recorded.

\section{Result}

Both the groups were comparable with each other to assess pain scores and analgesic requirements. Group $T$ had less pain at rest $(<0.001)$ on visual analogue scales and also less analgesic and opioids consumption compared to group $L$ $(<0.001)$, which were found to be statistically significant.

\section{Conclusion}

Subcostal transversus abdominis plane block is beneficial, effective and reliable method in providing post-operative analgesia in patients after laparoscopic cholecystectomy compared to local infiltration at port sites.

\section{KEYWORDS}

Local infiltration, laparoscopic surgery, Postoperative analgesia, subcostal transversus abdominis block, ultrasound, visual analogue score 


\section{INTRODUCTION}

Laparoscopic cholecystectomy is a safe and common procedure done for various symptomatic gallbladder diseases. Although it is minimally invasive, many of the patients experience moderate to severe pain in the early postoperative period. ${ }^{1}$ Pain after laparoscopic cholecystectomy has several origins: incisional, local, visceral, peritoneal and referred. ${ }^{2}$ Conventional opioid analgesia has its own side effects like nausea, vomiting, sedation and delayed discharge from the hospital. Transversus abdominis block has been frequently used to provide anaesthesia to the anterolateral wall. Pain after laparoscopic cholecystectomy is mediated via the segmental innervation by nociceptive afferent pathway along the transversus abdominis fascial plane., ${ }^{3,4}$ TAP block has an important role in postoperative analgesia after abdominal surgery because after the deposition of the local anaesthetics in the transversus abdominis plane, it will produce sensory block over the anterior abdominal wall from T7-T11. The main concern of pain after laparoscopic cholecystectomy is from the abdominal wall incision and many studies reported the benefits of TAP block only in surgery of lower abdominal wall.

Hebbard et.al in 2008, first described ultrasound guided subcostal transversus abdominis plane block (sTAP) which is a variation of TAP and covers the supraumbilical distribution of the block as well the entire abdomen. ${ }^{5}$ In the subcostal approach, the drug is deposited between the rectus abdominis and the transversus abdominis muscle. Thus T6T9 nerves supplying the upper abdomen just below the xiphoid and parallel to the costal margin are blocked. ${ }^{6,7}$ STAP is preferred for postoperative analgesia after laparoscopic cholecystectomy as it has decreased opioid consumption, faster hospital discharge and supraumbilical analgesia. ${ }^{8}$

The rationale of our present study was to compare the analgesic efficacy between bilateral sTAP block versus local port site infiltration and to evaluate the time of rescue analgesia and opioid consumption in all the patients undergoing laparoscopic cholecystectomy under general anaesthesia.

\section{METHODOLOGY}

This prospective randomized study was carried out in the Department of Anaesthesiology at Nobel Medical College Teaching Hospital from September 2020 to September 2021 after getting ethical clearance from the institutional review committee. Sixty patients of age group 18-60 years of either gender, of ASA physical status I and II with symptomatic gallstone diseases scheduled for laparoscopic cholecystectomy under General anesthesia and willing to participate in the study were enrolled. Exclusion criteria were patients unwilling to participate in the study, coagulopathies, allergy to local anaesthetics, patients with ASA III or more. Informed written consent was taken. Preanaesthetic checkup was done a day before surgery and the patients were introduced regarding the concept of the study and visual analogue scale(VAS ) in which 0 =means no pain and 10 =means worst pain imaginable. Prior to surgery patients were kept nil per oral for 8 hours. Premedication was done with tab. ranitidine $150 \mathrm{mg}$ orally. A total of 60 patients were divided into two groups of 30 each, viz. group $\mathrm{T}$ (sTAP block) and group L (local infiltration). In the operation theatre, as soon as the patient arrived, an $18 \mathrm{G}$ intravenous cannula was inserted in the non -dominant hand and ringer lactate was infused at a rate of $70 \mathrm{ml} / \mathrm{hr}$. As per ASA Standard recommendation non-invasive monitors were attached to monitor ECG, $\mathrm{HR}, \mathrm{NIBP}$ and $\mathrm{SPO}_{2}$. Induction was done with midazolam $(0.02 \mathrm{mg} / \mathrm{kg})$, fentanyl $(2 \mathrm{mcg} / \mathrm{kg})$, propofol $(2.5 \mathrm{mg} / \mathrm{kg})$ and vecuronium $(0.1 \mathrm{mg} / \mathrm{kg})$. After intubation, anaesthesia was maintained by $50 \% 02$ in air, isoflurane $1-1.5 \%$ and intermittent doses of vecuronium. Minute ventilation was maintained and adjusted to keep End tidal carbon dioxide $\left(\mathrm{ETCO}_{2}\right)$ below $45 \mathrm{~mm} \mathrm{Hg}$. At the end of the surgery, group $\mathrm{T}$ was administered ultrasound (US) guided subcostal TAP block bilaterally, with $20 \mathrm{ml}$ of $0.25 \%$ bupivacaine by an experienced anesthesiologist. Patients in group $L$ received local anesthesia at the port sites with $20 \mathrm{ml}$ of $0.25 \%$ bupivacaine by the operating surgeon. For group $\mathrm{T}$ under aseptic conditions the procedure was performed with the Sonosite M-turbo US with a linear probe of $6-13 \mathrm{MHz}$ using a $22 \mathrm{G} 100 \mathrm{~mm}$ stimuplex needle with an in-plane technique was applied. The probe was placed in horizontal position just under the xiphisternum and moved subcostal laterally until the transversus abdominis starts beneath the rectus abdominis muscle, the needle was guided and after aspiration $20 \mathrm{ml}$ of $0.25 \%$ bupivacaine was deposited between the rectus abdominis and the transversus abdominis plane. Patients were reversed after fulfilling extubation criteria and shifted to Post anaesthesia care Unit (PACU).

Pain scores were assessed at rest and on movement by a resident doctor blinded to the study to both the groups in PACU using VAS 0-1. VAS was assessed at $0 \mathrm{hr}$ and $2 \mathrm{hr}$ in PACU and then they were shifted to post operative ward after fulfilling the discharge criteria and henceforth pain scores were assessed there at 6, 12, and 24 hrs by the ward nurse and patients with VAS $>4$ were supplemented rescue analgesics. Postoperative nausea and vomiting were also recorded. SPSS was used for statistical analysis and for descriptive statistics percentage, mean and standard deviation were calculated along with graphical and tabular presentation. For inferential statistics Mann Whitney $U$ test was applied to find out the significant differences ( $p$ values $<0.05$ ) between groups and VAS scores,

\section{RESULTS}

Table 1: Baseline data of enrolled patients
\begin{tabular}{|r|l|l|l|}
\hline Patient data & \multicolumn{1}{|c|}{ group T } & \multicolumn{1}{|c|}{ group L } & p-value \\
\hline Age (years) \pm SD & $41.63 \pm 11.99$ & $40.23 \pm 11.42$ & 0.645 \\
\hline $\begin{array}{r}\text { Gender } \\
\text { Female } \\
\text { Male }\end{array}$ & $\begin{array}{l}25(83.3) \\
5(16.7)\end{array}$ & $\begin{array}{l}21(70.0) \\
9(30.0)\end{array}$ & 0.222 \\
\hline $\mathrm{DM}^{1}$ & $3(10.0)$ & $1(3.3)$ & 0.268 \\
\hline
\end{tabular}


Diabetes Mellitus

The baseline data were not significant with both groups. The mean age in years were $41.63 \pm 11.99$ and $40.23 \pm 11.42$ in STAP block and local infiltration respectively $(p=0.645)$. In gender, $16.67 \%$ and $30.0 \%$ were male $(p=0.222)$ and $10.0 \%$ and $3.3 \%$ had DM (diabetic mellitus) $(p=0.268)$ in sTAP block (group T) and Local infiltration (group L) respectively.

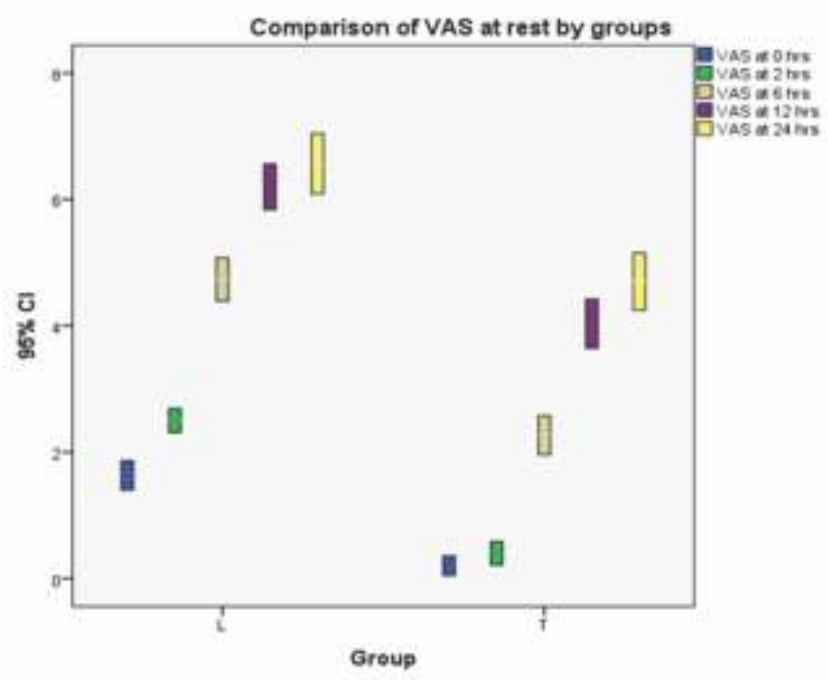

Figure 1: Post-operative VAS score in different time interval by Groups

Table 2: Level of Significant values between the groups

\begin{tabular}{|c|c|c|c|c|c|}
\hline Time & $\begin{array}{c}\text { VAS at } 0 \\
\text { hours }\end{array}$ & $\begin{array}{c}\text { VAS at } 2 \\
\text { hours }\end{array}$ & $\begin{array}{c}\text { VAS at } 6 \\
\text { hours }\end{array}$ & $\begin{array}{c}\text { VAS at 12 } \\
\text { hours }\end{array}$ & $\begin{array}{c}\text { VAS at } 24 \\
\text { hours }\end{array}$ \\
\hline$p$ values & $<0.001$ & $<0.001$ & $<0.001$ & $<0.001$ & $<0.001$ \\
\hline Remarks & Sig. & Sig. & Sig. & Sig. & Sig. \\
\hline
\end{tabular}

The post-operative pain score (VAS) at rest and movement was found to be significant at $0,2,6,12$, and 24 hours between the groups ie. STAP block (group T) and Local infiltration (group L) respectively. The VAS score was significantly high in group $L$ at different hours which was presented in above box-plot, where $p$ values were given in table below by using non-parametric Mann-Whitney test.

Table 3: Opioid consumption and rescue analgesia by
\begin{tabular}{|l|c|c|c|c|c|c|}
\hline \multirow{2}{*}{ Variable } & \multicolumn{2}{|c|}{ group T } & \multicolumn{2}{|c|}{ group L } & \multirow{2}{*}{ p value } & Remarks \\
\cline { 2 - 7 } & Mean & SD & Mean & SD & \\
\hline $\begin{array}{l}24 \text { Hour fentanyl } \\
\text { consumption(mcg/kg) }\end{array}$ & 24.67 & 24.17 & 79.00 & 18.63 & $<0.001$ & Sig \\
\hline Rescue Analgesia (Hour) & 3.45 & 1.12 & 1.75 & 0.70 & $<0.001$ & Sig \\
\hline
\end{tabular}

The 24-Hour fentanyl consumption was found to be significantly high in group $L(p<0.001)$ and the average Rescue Analgesia (Hour) for the patients in the same group, which was found to be highly significant $(p<0.001)$.

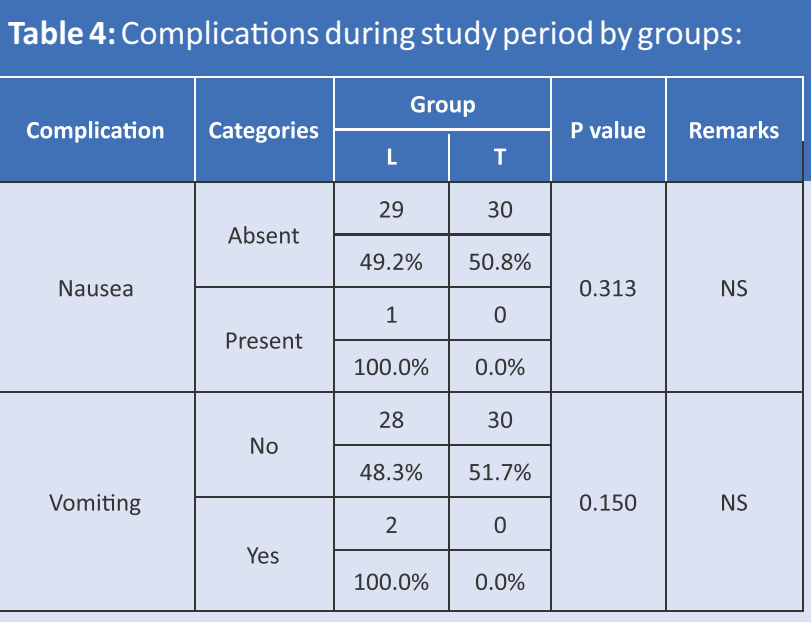

Complications like nausea and vomiting were not found to be significant between these two groups.

\section{DISCUSSION}

Laparoscopic cholecystectomy is an elective procedure widely performed. Patients suffer considerably on the day of surgery and analgesia is required frequently. Patients suffer from significant pain which is of parietal, visceral, incisional and referred postoperative pain. Placement of trocars through the abdominal wall causes parietal pain which is superficial in nature. Intraperitoneal dissection and insufflation of $\mathrm{CO} 2$, resulting in distension of the abdominal wall causes visceral pain which is dull, more diffuse than parietal pain, and difficult to locate. Referred shoulder tip pain is caused by the prolonged elevation of the diaphragm and residual gas from $\mathrm{CO} 2$ insufflation.

Poor pain control in the postoperative ward results in decreased patient satisfaction, delayed recovery and discharge from the hospital and increased postoperative complications. Traditionally opioid has been used to manage postoperative pain. Due to increasing awareness of opioid related adverse events including respiratory depression, paralytic ileus and sedation has led to shift towards utilizing opioid sparing technique for postoperative analgesia. Good postoperative analgesia is an important component of adequate perioperative care. It is associated with improved outcome, a reduction in perioperative stress, improved patient satisfaction and coupled with a reduction in opioid consumption and recovery time following elective laparoscopic surgery. The aim of treating postoperative pain is to eliminate or at least reduce pain to a minimum level, to accelerate the healing process and to avoid side effects that can emerge with treatment.

Ultrasound guided TAP blocks can be given through different approaches, currently the 3 main approaches are: posterior, subcostal and oblique subcostal. ${ }^{9}$ We have used the subcostal approach in our study as it blocks T6-L1 dermatome by depositing the drug bilaterally. Subcostal TAP block was reported to have provided effective and long lasting analgesics in the anterior abdominal wall from 
xiphopid to edge of lower abdomen. Classical TAP or TAP block has its own complications like liver injury, bowel hematoma, nerve injury, unpredictable spread of local anaesthetics with subsequent motor block. ${ }^{10-12}$ The ultrasound guided TAP blocks revolutionized this technique as a part of multimodal post operative pain management. ${ }^{13}$ Under ultrasound guidance most of the complications are reduced significantly because it increases the margin of safety by proper visualization of the anatomy, the needle shaft and tip thus deposition of local anaesthetic agents and spread between the layers are under direct vision. Hence, the volume of drug injected is less and success rate is increased. ${ }^{9}$ The Subcostal TAP block provides effective analgesia and covers the supra-umbilical distribution of the block as well as the entire abdomen.

The demonstrated analgesics efficacy of subcostal TAP in elective laparoscopic cholecystectomy is consistent with prior studies that demonstrate reduction in opioid analgesic requirement and reduced pain scores following TAP block in appendix, hysterectomy. ${ }^{14}$ Ultrasound guided TAP block facilitates the anatomical distribution of block whereas portside infiltration is infiltrated without any anatomical distribution. Port site infiltration of local anaesthetics blocks sensory nerves of the anterior abdominal wall but since it is a blind technique, the block can be unpredictable as the landmarks are not defined and the deposition of the drug in the correct anatomical plane is not confirmed. The improved quality of postoperative analgesia associated with STAP block further supports a growing body of evidence that TAP block is superior to traditional port infiltration technique. Many recent literatures have shown studies on multimodal analgesia to provide excellent analgesia in patients. Subcostal TAP block is an effective component of multimodal analgesia and is currently used in abdominal surgeries for post-operative pain management.

Recent studies have shown beneficial results for TAP block in giving postoperative analgesia for upto 24 hours following abdominal surgery. ${ }^{14,15}$ Subcostal TAP block effectively reduces opioid analgesic requirement in elective laparoscopic cholecystectomy and reduces the burden of these patients on recovery status. In our study 60 patients were equally divided into 30 patients in each group and were comparable in gender, age and ASA PS classification. ${ }^{8,16}$ The present study has showed that Post-operative pain was decreased significantly at $0,2,6,12$, and 24 hours at rest and on movement with the group receiving subcostal TAP block in comparison to local infiltration at port site as evidenced by lower VAS scores. There was decreased 24 hours opioid consumption and delayed request for first rescue analgesics in subcostal TAP block group. There was no local anaesthetic toxicity during the study in the 60 patients as we used ultrasound in real time and the drug volume was low. Nausea and vomiting was statistically insignificant ( $p$ value 0.313 and 0.150 ) as it might be due to decreased opioid consumption. The superior analgesia provided by subcostal TAP block extended the spread of analgesia upto dermatome T6 level where epigastric port is placed.

\section{CONCLUSION}

Subcostal transversus abdominis plane block is beneficial, effective and reliable method in providing post-operative analgesia in patients after laparoscopic cholecystectomy compared to local infiltration at port sites. It produced improved pain scores, less analgesic requirement and greater patient satisfaction.

\section{LIMITATION OF THE STUDY}

Patients with ASA physical status grade I and II were only involved in this study. So these results might not be applicable in patients with higher grades. The sample size of the study was small and was carried out at only one institution which was too small for broad generalization.

\section{ACKNOWLEDGEMENT}

We would like to acknowledge our HOD, Prof. C.R Das for his guidance and the Department of Anaesthesiology, Critical Care and Pain Management, who directly or indirectly helped us to complete the study.

\section{REFERENCES}

1. Kum CK, Wong CW, Goh PM, Ti TK. Comparative study of pain level and analgesic requirement after laparoscopic and open cholecystectomy. Surgical laparoscopy \& endoscopy. 1994 Apr 1;4(2):139-41.

2. Mitra S, Khandelwal P, Roberts K, Kumar S, Vadivelu N. Pain relief in laparoscopic cholecystectomy-a review of the current options. Pain Practice. 2012 Jul;12(6):485-96.

3. Johnson MZ, O'Connor TC. Excellent postoperative analgesia with the addition of hyaluronidase to lignocaine for subcostal TAP block used in conjunction with systemic analgesia for laparoscopic cholecystectomy. Case Reports. 2014 Feb 7;2014:bcr2013202911.
4. El-Dawlatly AA, Turkistani A, Kettner SC, Machata AM, Delvi MB, Thallaj A, Kapral S, Marhofer P. Ultrasound-guided transversus-abdominis plane block: description of a new technique and comparison with conventional systemic analgesia during laparoscopic cholecystectomy. British journal of anaesthesia. 2009 Jun 1;102(6):763-7.

5. Mavarez AC, Ahmed AA. Transabdominal Plane Block. StatPearls [Internet]. 2021 Jul 29.

6. Tsai HC, Yoshida T, Chuang TY, Yang SF, Chang CC, Yao HY, Tai YT, Lin JA, Chen KY. Transversusabdominis plane block: an updated review of anatomy and techniques. BioMed research international. 2017 Jan $1 ; 2017$. 
7. Kawahara R, Tamai Y, Yamasaki K, Okuno S, Hanada R, Funato T. The analgesic efficacy of ultrasound-guided transversusabdominis plane block with mid-axillary approach after gynecologic laparoscopic surgery: A randomized controlled trial. Journal of anaesthesiology, clinical pharmacology. 2015 Jan;31(1):67.

8. Peng $\mathrm{K}, \mathrm{Ji} \mathrm{FH}$, Liu HY, Wu SR. Ultrasound-guided transversusabdominis plane block for analgesia in laparoscopic cholecystectomy: a systematic review and meta-analysis. Medical Principles and Practice. 2016;25(3):237-46.

9. Hebbard P. Subcostal transversusabdominis plane block under ultrasound guidance. Anesthesia \& Analgesia. 2008 Feb 1;106(2): 6745.

10. Lancaster P, Chadwick M. Liver trauma secondary to ultrasoundguided transversusabdominis plane block. British journal of anaesthesia. 2010 Apr 1;104(4):509-10.

11. Mukhtar K. Transversusabdominis plane (TAP) block. The Journal of New York School of Regional Anesthesia. 2009 May;12:28-33.

12. McDermott G, Korba E, Mata U, Jaigirdar M, Narayanan N, Boylan J, Conlon N. Should we stop doing blind transversusabdominis plane blocks?. British journal of anaesthesia. 2012 Mar 1;108(3):499-502.
13. Yu N, Long X, Lujan-Hernandez JR, Succar J, Xin X, Wang X. Transversusabdominis-plane block versus local anesthetic wound infiltration in lower abdominal surgery: a systematic review and metaanalysis of randomized controlled trials. BMC anesthesiology. 2014 Dec;14(1):1-9.

14.McDonnell JG, Curley G, Carney J, Benton A, Costello J, Maharaj CH, Laffey JG. The analgesic efficacy of transversusabdominis plane block after cesarean delivery: a randomized controlled trial. Anesthesia \& Analgesia. 2008 Jan 1;106(1):186-91.

15. Kamhawy G, El-Taher E, Abdelrahman M. A comparison of oblique subcostal transversusabdominis plane block versus thoracic paravertebral block for postoperative analgesia after open cholecystectomy. Egyptian Journal of Anaesthesia. 2017 Oct 1;33(4):323-9.

16. Ibrahim M, Shamaa HE. Efficacy of ultrasound-guided oblique subcostal transversusabdominis plane block after laparoscopic sleeve gastrectomy: A double blind, randomized, placebo controlled study. Egyptian Journal of Anaesthesia. 2014 Jul 1;30(3):285-92.

17. Doyle DJ, Goyal A, Bansal P, Garmon EH. American society of anesthesiologists classification. InStatPearls [Internet] $2020 \mathrm{Jul} 4$. StatPearls Publishing. 